\title{
Migration Intentions and Alcohol Use Among Adolescents in West-Central Mexico
}

\author{
Flavio F. Marsiglia ${ }^{1}$ Shiyou Wu ${ }^{1}$ (D - SeungYong Han ${ }^{2} \cdot$ Bertha L. Nuño-Gutierrez ${ }^{3} \cdot$ Hilda García-Pérez $^{4}$. \\ Scott T. Yabiku ${ }^{5}$. Jennifer E. Glick ${ }^{5}$
}

Accepted: 15 March 2021 / Published online: 27 March 2021

(c) The Author(s), under exclusive licence to Springer Science+Business Media, LLC, part of Springer Nature 2021

\begin{abstract}
This study explores the association between migration intentions and alcohol use among west-central Mexico adolescents living in high migration communities. This study used the baseline data from the Family Migration and Early Life Outcomes (FAMELO) project $(N=1286)$, collected in 2018. We used multiple imputations to address missingness and propensity score matching to reduce the selection bias. We also conducted subgroup analyses to compare gender difference (i.e., boys vs. girls) on the relationship between migration intention and alcohol use. The findings show that for the whole sample, youth with migration intentions had significant higher odds $(\mathrm{OR}=1.78 ; p=.010)$ of having a lifetime drinking experience when compared to youth who reported no interest in living abroad, but this association remained significant only for boys $(\mathrm{OR}=2.14 ; p=.010)$. This study makes an important contribution to our understanding of the etiology of migration intentions and alcohol use for adolescents living in sending migration communities. The findings have specific alcohol prevention, policy, and future research implications in Mexico and the U.S.
\end{abstract}

Keywords Migration intentions $\cdot$ Alcohol use $\cdot$ Alcohol prevention $\cdot$ Mexico adolescent $\cdot$ Immigration stress $\cdot$ Ecological systems

This article reports on a study about the psychosocial experiences of youth from Central Mexico living in high migration communities. Our main purpose was to study possible associations between migration intentions and alcohol use of youth living in rural and semi-rural high migration communities. This research is relevant for Mexico as well as for the U.S. because Mexico is one of the largest sources of immigrants to the United States. Approximately 12,680,000

\section{Shiyou $\mathrm{Wu}$}

shiyou.wu@asu.edu

1 Global Center for Applied Health Research, School of Social Work, Arizona State University, 411 N. Central Ave., Suite 800, Phoenix, AZ 85287, USA

2 Edson College of Nursing and Health Innovation, Arizona State University, Phoenix, AZ, USA

3 Centro de Estudios e Investigaciones en Comportamiento, Universidad de Guadalajara, Guadalajara, Mexico

4 El Colegio de la Frontera Norte, Nogales, Mexico

5 Population Research Institute and Department of Sociology \& Criminology, Pennsylvania State University,

University Park, PA, USA individuals born in Mexico were residing in the U.S. in 2017, representing $25 \%$ of the total foreign-born population in the same year and less than half of the estimated undocumented immigrants in 2018 (Pew Research Center, 2019a, 2019b). There are many forces that encourage migration and as many theories attempting to explain these complex processes.

The new home economics perspective on migration describes the fluid migration pattern between neighboring countries as a household level coping strategy to diversify income and reduce risk (Massey et al., 1993). The most common pattern is that the individual migrates and remits part of her/his income to the family, thus helping to diversify the resources available to the household (Hazán, 2014). The new home economics perspective attempts to overcome two major limitations of the neoclassical economics perspective: a perfect rationality and a decision-making solely at the individual level (Jennissen, 2007; Massey et al., 1993). Despite the different theoretical emphasis on why people migrate, there is consensus in the field that large sectors of the population of Mexico have high intentions to migrate internationally, mostly to the USA. 
According to some estimates, about $45 \%$ of all immigrants in the U.S. are undocumented, which makes it more difficult to produce precise migration numbers (GonzalezBarrera \& Krogstad, 2018). The high rates of documented and undocumented migration across the U.S.-Mexico border, however, foretells high levels of migration intention among young people. Intentions to migrate to the U.S. predicts subsequent migration to the U.S. on the part of Mexican youth. Similarly, intentions to inter-municipal and interstate migration are predictive of subsequent inter-municipal and interstate migration within Mexico (Creighton, 2013).

\section{Intentions to Migrate}

Distinct from actual behavior, intentions to migrate is the intent, desire, consideration, inclination, plan, or preparation of individuals to migrate (Carling, 2017). Dreaming of a better life abroad is not the same than the expectation to emigrate in the near future (Van Dalen \& Henkens, 2013). The percent of people reporting intentions or aspirations to migrate is always higher than the percent of those who have an expectation to emigrate and those who actually leave (Esipova et al., 2011a, 2011b). A study using data from traditionally sending countries found that intentions to migrate and actual migration flow are strongly associated and that both lead to international migration in some cases (Tjaden et al., 2019). We do not know much, however, about the youth who have intentions to migrate but do not migrate after all.

The migration literature often identifies higher educational levels and being young as the main predictors of intentions to migrate (de Haas, 2010). Geographic dyadic variables provide a more nuanced perspective by considering other variables such as distance between the place of origin of potential migrants and their desired destination and the existence of networks at destination for high and low educated individuals (Dao et al., 2018). Income appears to be a significant determinant of the aspirations to migrate of only low educated individuals while age is a consistent factor for individuals aged 15-19, across all groups of countries (Migali \& Scipioni, 2019). Youth with strong networks in the receiving country and relatives who send remittances tend to have higher intentions to migrate (Bertoli \& Ruyssen, 2018). While youth with strong social bonds and networks in their country of origin, tend to stay despite their aspirations to migrate (Manchin \& Orazbayev, 2018).

There is also a gender dimension to migration aspirations. In many societies, women are becoming more aware of their rights and speak-up about gender discrimination; their intentions to migrate are also increasing (Ryussen \& Salomone, 2018). More females in Mexico and Central America are preparing themselves for their migration journeys. In rural areas, the intentions to migrate have been traditionally stronger among males. In communities with more traditional gender roles women tend to stay behind as their boyfriends or husbands migrate north (Kulis et al., 2012). In some regions, however, young females are migrating at higher rates than males (Buechler \& Lutz-Ley, 2020).

Intentions to migrate -as migration itself- is a complex multifactor phenomenon, which occurs in context, and it is influenced by a diversity of macro, meso and micro level factors, influencing the youth (Chu \& Thelamour, 2021). The geographic proximity and historical links between Mexico and the USA and the pronounced income disparity between the two countries present a very interesting case study with potential implications for both countries.

A strong predictor of migration intentions among lowincome Mexican youth is the presence of migrants in the family or social network in the U.S. (Jensen et al., 2018). Migrants contribute considerable financial resources into communities around Mexico through remittances (Levitt, 1998, 2001). Residents in communities experiencing high rates of migration also incorporate new ideas and values, which in turn, can influence their behaviors in positive or negative ways (Dabir et al., 2013). In addition, youth in families with migrant parents are more likely to plan their own migration and often reduce their engagement in school at their home country (Jensen et al., 2018).

\section{Youth Substance Use}

A potential negative outcome of migration at the individual level, particularly among vulnerable youth, is substance use. A series of studies in Mexico and the U.S. examined the effects of exposure to U.S. norms related to alcohol and other drugs on Mexican migrants and returned migrants (Borges et al., 2007, 2009, 2012a, 2016, 2018; Marsiglia et al., 2012). The results revealed that the migration experience to the U.S., particularly of returned migrants, was associated with higher likelihood of alcohol use (Borges et al., 2011). There is also an assumption that migrants influence their communities of origin in Mexico but it is unclear how young people in high migration communities react to the substance use and abuse norms and behaviors espoused by their migrating older compatriots.

This study focuses on youth residing in high migration sending communities in the state of Jalisco, in west- central Mexico. Jalisco is one of the three states with the highest prevalence of binge drinking in Mexico: Nuevo León (30.3\%), Jalisco (27.7\%) and, Coahuila (27.5\%) (Escobar et al., 2018). Due to the young age of the participants, this study focuses on migration intentions (more abstract) rather than expectations (more concrete). Although most of these 
youth have not yet engaged in migration themselves, migration is certainly part of their social landscape.

This article reports on the findings of a study that aimed at expanding on previous research (Marsiglia et al., 2011) about the experiences of youth from Central Mexico's high migration communities. We approached the phenomenon form an ecological systems approach (Bronfenbrenner, 1992). This theory allows us to consider how different domains in the social ecology of young people's lives influence their behavior and wellbeing. Specifically we will investigate if intentions to migrate and alcohol use are associated. Our models will include key variables from the most proximal ecosystems (i.e., micro and meso) that are often associated with adolescent development (Bronfenbrenner, 2005). We hypothesize that youth residing in households and communities with a history of migration may present higher levels of vulnerability towards alcohol use. This vulnerability might be the result of a combination of many factors such as easier access to alcohol due to higher income from remittances, higher stress levels associated with migration and the incorporation of more flexible U.S.-based substance use norms within the family and community introduced by returning migrants (Hamilton, 2020). It is not clear, however, if the youths' own intention to migrate influences their attitudes and behaviors towards alcohol use. We aimed at advancing knowledge about the relationship between intentions to migrate and the youths' attitudes and behaviors towards alcohol use. Such research could inform current prevention efforts with and for youth in Mexico (Marsiglia et al., 2019).

From an ecological systems approach (Bronfenbrenner, 1992), the study's main hypothesis is that youth from rural and semi-rural high migration communities with stronger intentions to migrate will report using alcohol more frequently when compared to their peers from the same communities who do not have strong intentions to migrate. The main aim of the study was to advance knowledge about risk and resiliency factors influencing youth's health in high migration communities who express an intention to migrate but who has not yet migrated or have returned. The voluntary or involuntary circular migration partners between the U.S. and Mexico continue to include historical sending communities in Mexico and an expanding number of states in the U.S. far beyond the traditional receiving states such as California, Texas and Illinois (Martinez \& Martinez, 2020). Southbound migrants returning from the border tend to report worse self-rated health and deportees had higher odds of reported substance use compared with northbound migrants without U.S. migration experience (Martinez-Donate et al., 2020). Young people living in Mexico sending communities are part of families that send migrants north, receive returnees (Denier \& Masferrer, 2020). Thus, young people encounter an assortment of changing norms and behaviors about alcohol use within their homes and communities.

The findings will inform future prevention interventions, policy and research in this area. This new knowledge has the potential of benefiting the local communities in Mexico and the USA as many of the participating youth from historically labor migration sending communities will eventually reside in the USA (Bach, 2020).

\section{Adolescent Alcohol Use in Mexico}

Alcohol use, particularly among teens, is a serious global health concern because early-age alcohol use is linked to many short- and long-term negative health consequences, such as school-related problems, brain and cognitive underdevelopment, and negative physical and psychological outcomes in later life (CDC, 2018a, b; Marshall, 2015). Alcohol use among adolescents in Mexico is also a national health concern. Mexican children and adolescents have experienced significant increases in their prevalence of substance use in the last 20 years (Vazquez et al., 2019). In 2014, 19\% and $16 \%$ of male and female adolescents attending middle school and high school, respectively, reported some level of alcohol use during their lifetime (Villatoro-Velázquez et al., 2015). The fast rise in the rates of alcohol use among female adolescents is adding urgency to the existing concern. In 2011, $8.6 \%$ of female adolescents (ages 12-18) reported excessive alcohol use and this percent almost doubled (14.9\%) by 2016 .

The gender gap in excessive alcohol use narrowed from $6.9 \%$ in 2011 to $0.6 \%$ in 2016 (Villatoro-Velázquez et al., 2015). There is a lack of knowledge about the etiology of this increase in alcohol use rates among young men and women but intentions to migrate could be a possible trigger. More recently, high numbers of families have voluntarily or involuntarily returned to Mexico after living many years in the U.S. (Denier \& Masferrer, 2020). Children in these families often do not speak Spanish and do not understand the local cultural norms which may make them more vulnerable to engaging in risky behaviors such as alcohol use (Caldwell, 2019).

The existing demographic and epidemiological data show that female adolescents in many communities in Mexico intend to migrate internationally and that Mexican youth regardless of gender report high levels of alcohol use. Most adolescents, however, are not old enough to have had prior migration experiences, which limits the implications of the previous studies examining the association between migration and substance use. Previous research has identified an association between intentions to migrate and alcohol use among adolescents residing in central Mexico (Marsiglia 
et al., 2011, 2012). Stronger intentions to migrate among youth ages 14 to 24 was associated with greater access to drugs, drug offers, and illicit drug use (including marijuana, cocaine, and inhalants). The association, however, was not significant for alcohol or cigarette use. Our previous research argued that this pattern is mainly due to a high community expectation that young adolescents migrate in order to help support their households. As a result, community members looked down at young people who did not migrate; the failure to migrate made them unsuccessful and more vulnerable to substance use (Marsiglia et al., 2011). Retrospective studies with Mexican returnees have also found that the impacts of immigration on substance use risk are stronger for illegal drugs than for alcohol (Borges et al., 2012b).

\section{Intentions to Migrate in Historical Sending Communities}

The push to migrate appears to be especially strong in historical sending communities (Kandel \& Massey, 2002). To handle the stress coming from the pressure and the failure to migrate, stay behind youth might be using alcohol and other drugs as a form of self-medicating (Deykin et al., 1987; Khantzian, 1985; Klee \& Reid, 1998; Wu et al., 2003). There might be gender variations in how boys and girls deal with the pressures of migration. For example, a Lithuanian study (Markšaitytė, 2010) found that migration intentions of males were associated with psychological characteristics, such as willingness to take risks. While for females, psychological well-being characteristics such as life satisfaction, daily life stress, and depression were associated with migration intentions. This leads to the need to examine possible unique differences by gender.

A connection between perceived life satisfaction and alcohol use has been also reported (Zullig, 2001). A global report of intentions to migrate states that those who intend to migrate tend to be less satisfied than individual in the general population. Overall, individuals that express lower satisfaction are young males and adults who believe that their children have limited opportunities in their home country (Migali \& Scipioni, 2018).

The ecological systems theory identifies multiple embedded systems that influence children and youth development (Bronfenbrenner, 2005). It identifies family, peers, and school (microsystem), the connections and interactions between them (the mesosystem), indirect environments such parents' workplace and labor related migration experiences (exosystems), and broader systems such as social norms and culture of origin (macrosystem) as influencing children's attitudes and behaviors toward the behaviors of interest in this study (Bronfenbrenner, 1992).
The present research relies on data collected directly from adolescents and adults in the same home, with detailed information on households, relationships, migration and child behaviors. We will focus only on the individual adolescent and her his immediate household environment and the interaction of these two ecological systems knowing that all the participating households are located within high sending migration communities. Six out of ten Mexican migrants to the USA are men and eight out of ten are between the ages of 15 to 64 (Bermudez \& Reyes, 2015). Labor migration among women is less normative in Jalisco than among men just as alcohol consumption is more normative among boys than among girls. Findings from studies with communities along or close to the Mexico-U.S. border report higher intentions to migrate among girls ((Buechler \& Lutz-Ley, 2020). Based on these recent findings from the northern border, it is important to test more accepted assumption that the connection between migration intentions and higher alcohol use is stronger among boys than among girls (Kulis et al., 2018).

The current study examined if there was an association between intentions to migrate and alcohol use in a western Mexico context. We hypothesize that:

$\mathrm{H}_{1}$ : There will be an association between migration intention and alcohol use among adolescents, and

$\mathrm{H}_{2}$ : The association between intentions to migrate and alcohol use will be stronger for boys than for girls.

\section{Methods}

\section{Data and Sample}

The data used for this study is from the baseline data of the Family Migration and Early Life Outcomes (FAMELO) project. We are analyzing data from the first wave of pre-intervention data, collected in 2018. The second wave of data collection was interrupted by the COVID-19 pandemic. The data is germane to examining the association between migration intention and alcohol use among adolescents because of the detailed information about migration intentions of focal children and the additional migration experience information of all family members in the same household.

FAMELO is an on-going multinational project implemented in Mexico, Mozambique, and Nepal with the purpose of understanding how family migration influences children left behind in their countries of origin. The state of Jalisco was chosen as the focal site for Mexico. Jalisco is located in the Western region of Mexico and it is the third most developed state in the country, and one of the four states with the highest density of migration to the USA. 
Sixty percent of the municipalities of Jalisco have high to very high migration rates (CONAPO, 2015).

For the FAMELO study, communities throughout the state of Jalisco were sampled from the group of municipalities rated as having high scores (i.e., 80th percentile or higher) on the migration intensity index developed by CONAPO (2016). Interviewers visited households within chosen blocks, and households were screened for eligibility. A household was considered eligible to participate if it had at least one child age 5-17 living in the household, unless the child was the head or spouse of their own household, and one adult with primary responsibility for the child. Interviews were conducted with the adult caregiver and at least one focal child, one per household. In half of the sampled households, a second randomly chosen focal child was interviewed.

The final Wave 1 of the FAMELO sample in Jalisco included 2268 adults and 3,249 children interviewed between the end of 2017 and early 2018. The interviews included detailed information about the migration history of all household members including those who were away from households at the time of the survey. The data also has detailed information on migration intention of focal children, their educational activities and self-reported health and development as well as household composition and relationships between all household members.

Jalisco is an appropriate site for this study as it has been a historical 'sending' region for international migration with sporadic changes in flows in response to economic and political circumstances in the United States and locally (Durand et al., 2001; Masferrer \& Roberts, 2012). Although, out migration from Jalisco to the United States has decelerated in recent years, it continues to be significant within the Mexico context (Leyva-Flores et al., 2018). Guadalajara is Jalisco's capital; the largest city in the state and home to many internal migrants.

Jalisco is home to tequila and alcohol use is normative and pervasive, as reflected by its very high alcohol consumption rates. Jalisco is a state with one of the highest alcohol use rates in Mexico (80\%), high above the national average (71.7\%). In 2016, alcohol consumption rates among adolescents-at least once in a lifetime-was $42.9 \%$, last year was $28.8 \%$ and excessive consumption was $8.3 \%$, all above national averages (ENCODAT, 2017). Jalisco was identified as being at very high risk in a study applying the Index of Macrosocial Risk of Drug Use (IRMCD) in municipalities and delegations in Mexico (Rodríguez-Kuri et al., 2019). The IRMCD identified macrosocial conditions that presumably place individuals at a high or very high risk of substance use. Some of macrosocial factors considered by the IRMCD include the location of a municipality on a drug trafficking or production route (volume of drug seizures), state prevalence of use in the student population, presence of places where alcohol is sold, and Socioeconomic Status (SES) and inequality among the population (Rodríguez-Kuri et al., 2019).

Since our analytic focus is on adolescents, the final analytic sample used for this study includes 1286 focal children (622 females and 664 males) between ages 12 and 17. Out of those 1286 focal children, 854 come from households with one focal child interview and the rest come from 216 households where interviews were conducted with two focal children.

\section{Measurements}

\section{Alcohol Use}

The dependent variable of this study was whether adolescents were currently using alcohol at the time they took the survey. Focal children were asked how often they drink alcohol at the time of the survey. Scores were based on responses of $1=$ "never", 2 = "rarely", $3=$ "sometimes", $4=$ =often", and $5=$ "always". Since alcohol frequency is right-skewed with many children without drinking experience (e.g., more than $80 \%$ of children younger than 15 years old), the variable was dichotomized as currently using alcohol, with 1 representing any drinking experience (rarely through always) whereas 0 representing not using.

\section{Migration Intentions}

Two types of intentions to migrate to a foreign country were assessed by two interview questions: "Where would you most likely live when you grow up?" and "Do you think you will ever live somewhere other than this community?" The first question was intended to measure migration intention while the second question was intended to measure migration expectation. Youth were able answer these two questions using the same Likert scale: $1-$ Here in this community/municipality, 2-Guadalajara, 3-Somewhere else in Jalisco, 4-Somewhere else in Mexico, 5-In another country. Youth were considered to have migration intentions (1) if they answered "in another country" to either question. All other answers were coded as having no intention to migrate internationally $(0)$.

\section{Migration History}

The survey asked multiple questions about migration experience in the past to each of household members. For analysis, migration experience of focal child, parents and siblings was used. Since there were numerous focal children without one or both parents ( 1 focal child without both parents and 76 focal children without either mother or father), migration 
experience of both, one or neither parent was used. The purpose of migration could not be utilized for the study because it was only asked for the most recent migration experience.

\section{Youth, Parental, and Household Characteristics}

A few known factors associated with migration intention and alcohol use were included in the logistic regression model to create propensity scores (Massey et al., 1993, 1994). Youth characteristics included factors such as age, ever repeated the same grade, being in secondary education (i.e., in junior high and high school), being born in the same town, migration experience in the past, self-rated health (very good health, good health, only ok health, bad health, or very bad health), subjective household socioeconomic status (SES), poor perception of life in the U.S., and using English as a second language. Parental characteristics included age, education, and having a parent born in the same town. For age and education, a higher age and a higher level of education between mother and father were considered in case both parents were alive at the time of the survey. Lastly, we controlled the total household size including those who were away from the household at the time of the survey.

\section{Analytic Strategies}

First, we conducted multiple imputation to address the missing data using Stata 15.0 (i.e., using "mi" syntax to estimate missing values by chained equations). Twenty imputed files were generated for further analysis. All the following analyses and results were based on the aggregation of the 20 imputed files.

Second, based on the imputed data, we conducted propensity score matching in order to reduce the selection bias of the two groups of having or not having intentions to migrate. The purpose of propensity score matching is to mimic what happens in randomized controlled trials with observational data by balancing observed covariates between subjects in control and treatment study groups (Guo \& Fraser, 2015). Therefore, propensity score analysis seeks to reduce the sample selection bias for cross-sectional survey data. The logistic regression model included all available observed factors that are found to be associated both with migration intention and alcohol use based on previous studies. After matching, the final logistic regression model also controlled for those factors to be sure that we controlled for all the possible differences between the treatment and the control groups even after matching.

Propensity score radius matching (also called full matching) method was used because this approach can keep as many cases as possible in the analyses. We adopted 0.01 as the caliper (Rosenbaum \& Rubin, 1985) within the common-support region for the radius matching. We also conducted balance checks and found that 6 out of 17 control variables had significantly differences between the two groups before matching, whereas none of them remained significant differences after matching. The balance check results indicated that the matching process was preformed appropriately, the sample selection bias was reduced and the two groups were balanced.

Last, aggregated logistic regressions on the 20 imputed files were used to test the relationship between migration intention and alcohol use. We also conducted subgroup analyses to compare gender difference (i.e., male vs. female) on the relationship between migration intention and the odds of alcohol use among youth. Further, to triangulate the main analytic results based on imputed and matched data, we reported three additional regression results based on three other permutations of data: the raw data, imputed data only, and the balanced data only (i.e., using propensity score matching method). We used Stata 15.0 to run all analyses.

\section{Results}

\section{Descriptive Results}

Table 1 presents the descriptive statistics for all the variables related to migration intentions before imputation (see column a) and after imputation (see column b). About onefifth of the youth reported that they had an intention to live in another country when they grow up.

Overall, about $26 \%$ of the respondents had drinking experience. We controlled for variables at the individual youth and at their household levels. The sample had slightly less females (48\%) than males; the average age was 14.3 years. About $29 \%$ of youth were born in the same town where they currently reside. Most of respondents (76\%) attended middle school (secundarias), about $11 \%$ of the participants had ever repeated a grade. The average self-rated health score was $1.88(1=$ very good to $4=$ bad $)$ and $\mathrm{SD}=0.72$. About half (46\%) of the youth perceived that living in the U.S. could be a bad experience. Only $4 \%$ had a migration experience, and 6\% used English as a second language at home.

At the parental and household level, the average parental age was about 45 years old, and $81 \%$ of youth's parents were born in the same town they live in currently. About $29 \%$ of youth parents' education level was less than primary school, $60 \%$ had completed a primary school, and about $11 \%$ of them had an educational level higher than primary school. About one fourth of the youth's parents had a migration experience, and $12 \%$ of their siblings had migration experiences. More than half $(56 \%)$ of the participants had a motorcycle or car at home. The average household size of the participants was about five persons. 
Table 1 Sample descriptive statistics before and after matching

\begin{tabular}{|c|c|c|c|c|c|c|c|c|c|}
\hline \multirow[t]{2}{*}{ Variables } & \multicolumn{5}{|c|}{ (a) Before imputation } & \multicolumn{4}{|c|}{$\begin{array}{l}\text { (b) After imputation } \\
(\mathrm{n}=1286)\end{array}$} \\
\hline & $n$ & Mean & $S D$ & Min. & Max. & Mean & $S E$ & Min. & Max. \\
\hline \multicolumn{10}{|l|}{ Dependent variable } \\
\hline Drinking experience & 1266 & 0.26 & 0.44 & 0 & 1 & 0.26 & 0.01 & 0 & 1 \\
\hline \multicolumn{10}{|l|}{ Independent variables } \\
\hline Migration intention & 1237 & 0.21 & 0.41 & 0 & 1 & 0.21 & 0.01 & 0 & 1 \\
\hline \multicolumn{10}{|l|}{ Covariates } \\
\hline \multicolumn{10}{|l|}{ Youth level } \\
\hline Female & 1286 & 0.48 & 0.50 & 0 & 1 & 0.48 & 0.01 & 0 & 1 \\
\hline Age & 1286 & 14.33 & 1.63 & 12 & 17 & 14.33 & 0.05 & 12 & 17 \\
\hline Born in the same town & 1284 & 0.29 & 0.46 & 0 & 1 & 0.29 & 0.01 & 0 & 1 \\
\hline In secondary education & 1286 & 0.76 & 0.43 & 0 & 1 & 0.76 & 0.01 & 0 & 1 \\
\hline Self-rated health & 1279 & 1.88 & 0.72 & 0 & 3 & 1.88 & 0.02 & 0 & 3 \\
\hline Ever repeated the same grade & 1276 & 0.11 & 0.32 & 0 & 1 & 0.10 & 0.01 & 0 & 1 \\
\hline Poor perceived life in the U.S & 1245 & 0.46 & 0.50 & 0 & 1 & 0.46 & 0.01 & 0 & 1 \\
\hline Ever had migration experience & 1186 & 0.04 & 0.19 & 0 & 1 & 0.04 & 0.01 & 0 & 1 \\
\hline English as a second language & 1286 & 0.06 & 0.24 & 0 & 1 & 0.06 & 0.01 & 0 & 1 \\
\hline \multicolumn{10}{|l|}{ Parental/household level } \\
\hline Parental age & 1257 & 44.89 & 8.29 & 26 & 91 & 44.89 & 0.23 & 26 & 91 \\
\hline Parents were born in the same town & 1256 & 0.81 & 0.39 & 0 & 1 & 0.81 & 0.39 & 0 & 1 \\
\hline Parent(s) had migration experience & 1286 & 0.24 & 0.43 & 0 & 1 & 0.24 & 0.01 & 0 & 1 \\
\hline Sibling(s) had migration experience & 1286 & 0.12 & 0.32 & 0 & 1 & 0.12 & 0.01 & 0 & 1 \\
\hline Household size & 1286 & 4.87 & 1.46 & 2 & 12 & 4.87 & 0.04 & 2 & 12 \\
\hline \multicolumn{10}{|l|}{ Parental education } \\
\hline Less than primary school & 1257 & 0.29 & 0.46 & 0 & 1 & 0.29 & 0.01 & 0 & 1 \\
\hline Primary school & 1257 & 0.60 & 0.49 & 0 & 1 & 0.60 & 0.01 & 0 & 1 \\
\hline Higher than primary school & 1257 & 0.11 & 0.31 & 0 & 1 & 0.11 & 0.01 & 0 & 1 \\
\hline
\end{tabular}

\section{Relationships Between Youth Migration Intention and Drinking}

Table 2, column a, shows the regression results exploring the relationship between migration intention and drinking experiences among Jalisco youth in Mexico. Youth with migration intentions had significantly higher odds by $78 \%$ $(\mathrm{OR}=1.78 ; p=0.010)$ of having had a drinking experience. In addition, Table 2, column $\mathrm{b}$ and $\mathrm{c}$ present the subgroup analyses of comparing the probability of having drinking experience of youth with and without migration intentions among females and males. Results showed that only males who had migration intention had significantly higher odds by $114 \%(\mathrm{OR}=2.14 ; p=0.010)$ of having had a drinking experience than their male counterparts without migration intentions. The results, however, showed no statistically significant group differences in the odds of having drinking experience among females with or without migration intentions.

Regarding the covariates for the whole sample, all things being equal, females had a significantly lower odds of having a drinking experience than their male counterparts by $45 \%(\mathrm{OR}=0.55, p=0.004)$, while youth who used English as a second language had a significantly higher odds of having a drinking experience by $213 \%(\mathrm{OR}=3.13$, $p=0.005)$. As youth age increased by one year, the odds of having a drinking experience increased by $89 \%$ $(\mathrm{OR}=1.89, p<0.001)$. Household size appears to also matter. Every additional person increasing the household size marginally significant increased the odds of having a drinking experience by $16 \%(\mathrm{OR}=1.16, p=.051)$.

For the female subsample (Table 2, column b), other things being equal, being older, in secondary education, and using English as a second language at home were associated with significantly higher odds of having a drinking experience. For the male subsample (Table 2, column c), other things being equal, being older, perceiving that it is bad to live in the U.S., and coming from a larger size household were associated with significantly higher odds of drinking (see Table 2 for more details).

Table 3 shows the sensitivity tests results based on raw, imputed, and matched data, showing consistency with the main analytic results in Table 2 . Overall, youth 
Table 2 Regression results of migration intentions on drinking by whole, female, and male

\begin{tabular}{|c|c|c|c|c|c|c|c|c|c|}
\hline \multirow[t]{2}{*}{ Variables } & \multicolumn{3}{|c|}{$\begin{array}{l}\text { (a) Whole } \\
(n=1286)\end{array}$} & \multicolumn{3}{|c|}{$\begin{array}{l}\text { (b) Female } \\
(n=622)\end{array}$} & \multicolumn{3}{|c|}{$\begin{array}{l}\text { (c) Male } \\
(n=664)\end{array}$} \\
\hline & $O R$ & {$[95 \% \mathrm{CI}]$} & $P$ & $O R$ & {$[95 \% \mathrm{CI}]$} & $P$ & $\overline{O R}$ & {$[95 \% \mathrm{CI}]$} & $P$ \\
\hline Migration intention & 1.78 & [1.15-2.77] & 0.010 & 1.27 & {$[0.62-2.61]$} & 0.508 & 2.14 & {$[1.21-3.81]$} & 0.010 \\
\hline Female & 0.55 & {$[0.36-0.83]$} & 0.004 & - & - & - & - & - & - \\
\hline Age & 1.89 & [1.62-2.21] & 0.000 & 1.66 & {$[1.31-2.10]$} & 0.000 & 2.05 & {$[1.65-2.53]$} & 0.000 \\
\hline Born in the same town & 0.85 & [0.52-1.39] & 0.514 & 0.72 & {$[0.29-1.78]$} & 0.475 & 0.94 & {$[0.50-1.75]$} & 0.839 \\
\hline In secondary education & 1.24 & {$[0.66-2.33]$} & 0.510 & 5.38 & {$[0.84-34.21]$} & 0.075 & 0.86 & {$[0.40-1.85]$} & 0.691 \\
\hline Self-rated health & 0.85 & {$[0.63-1.13]$} & 0.257 & 0.72 & {$[0.46-1.12]$} & 0.144 & 0.96 & {$[0.62-1.47]$} & 0.836 \\
\hline Ever repeated the same grade & 1.00 & {$[0.50-1.99]$} & 0.999 & 0.40 & {$[0.05-3.29]$} & 0.388 & 1.18 & {$[0.55-2.52]$} & 0.673 \\
\hline Poor perceived life in the U.S & 1.41 & {$[0.93-2.14]$} & 0.104 & 0.95 & {$[0.47-1.94]$} & 0.897 & 1.86 & {$[1.08-3.18]$} & 0.024 \\
\hline Ever had migration experience & 1.60 & {$[0.49-5.25]$} & 0.438 & 1.34 & {$[0.12-14.70]$} & 0.810 & 2.14 & {$[0.54-8.58]$} & 0.280 \\
\hline English as a second language & 3.13 & {$[1.41-6.92]$} & 0.005 & 4.50 & {$[1.45-13.97]$} & 0.009 & 2.53 & {$[0.79-8.09]$} & 0.118 \\
\hline Parental age & 1.02 & {$[0.99-1.05]$} & 0.191 & 1.02 & {$[0.97-1.07]$} & 0.362 & 1.02 & {$[0.99-1.06]$} & 0.232 \\
\hline Parents were born in the same town & 0.95 & {$[0.54-1.65]$} & 0.846 & 0.79 & {$[0.31-2.01]$} & 0.623 & 1.03 & {$[0.52-2.02]$} & 0.941 \\
\hline Parent(s) had migration experience & 0.83 & {$[0.47-1.45]$} & 0.514 & 0.59 & {$[0.25-1.38]$} & 0.225 & 1.00 & {$[0.48-2.11]$} & 0.993 \\
\hline Sibling(s) had migration experience & 0.81 & {$[0.39-1.67]$} & 0.561 & 1.23 & {$[0.31-4.84]$} & 0.762 & 0.58 & {$[0.24-1.40]$} & 0.225 \\
\hline Household size & 1.16 & {$[1.00-1.35]$} & $\mathbf{0 . 0 5 1}$ & 1.12 & {$[0.87-1.44]$} & 0.360 & 1.18 & {$[0.98-1.41]$} & 0.075 \\
\hline $\begin{array}{l}\text { Parental education } \\
\text { Primary school }\end{array}$ & 0.86 & {$[0.52-1.42]$} & 0.564 & 0.85 & {$[0.41-1.77]$} & 0.658 & 0.89 & {$[0.46-1.73]$} & 0.738 \\
\hline Higher than primary school & 1.22 & {$[0.60-2.48]$} & 0.589 & 1.04 & {$[0.33-3.24]$} & 0.951 & 1.34 & {$[0.53-3.36]$} & 0.538 \\
\hline
\end{tabular}

$O R$ odds ratio, $C I$ confidence interval, (marginally) significant ORs were in bold

Table 3 Sensitivity tests: regression results of migration intentions on drinking by whole, female, and male

\begin{tabular}{llll}
\hline Migration intention & $(1)$ & $(2)$ & $(3)$ \\
& Whole & Female & Male \\
\hline Raw data & $1.91 * *$ & 1.22 & $2.53^{* * *}$ \\
& {$[1.29-2.83]$} & {$[0.64-2.33]$} & {$[1.53-4.18]$} \\
$n$ & 1,056 & 507 & 549 \\
PSM only & $1.82 * *$ & 1.13 & $2.42^{* *}$ \\
& {$[1.19-2.80]$} & {$[0.55-2.34]$} & {$[1.35-4.32]$} \\
$n$ & 806 & 347 & 432 \\
MI only & $1.99 * * *$ & 1.37 & $2.54 * * *$ \\
& {$[1.39-2.85]$} & {$[0.76-2.47]$} & {$[1.60-4.03]$} \\
$n$ & 1,286 & 662 & 664 \\
MI + PSM (Main Model) & $1.78 *$ & 1.27 & $2.14 *$ \\
& {$[1.15-2.77]$} & {$[0.62-2.61]$} & {$[1.21-3.81]$} \\
$n$ & 1,073 & 497 & 565 \\
\hline
\end{tabular}

$* * * p<.001 ; * * p<.01 ; * p<.05$

with migration intentions had significantly higher odds of drinking alcohol in the past, but in separate analyses by gender, these effects were only seen in males and not in females.

\section{Discussion}

The findings confirmed both hypotheses. Overall, youth with migration intentions had nearly a doubling of the odds of having a drinking experience when compared to youth who reported no interest in living abroad. This finding confirms previous research conducted in Mexico (Marsiglia et al., 2011, 2012). These previous studies found that the association between intentions to migrate and alcohol use varied by gender. Previous research reported that males with intentions to migrate had significantly higher odds of having a drinking experience than females with similar intentions to migrate. In other words, males with intentions to migrate were at a significantly higher risk for alcohol use than females. The present findings confirm previous findings; females reporting high intentions to migrate were not at a significantly higher risk for alcohol use than other females with no intentions to migrate. There were, however, small effects for females, which merit additional examination.

This finding contributes to the existing knowledge about the fast epidemiological changes and related motivations to migrate by gender in many countries, including Mexico (Markšaitytė, 2010; Villatoro-Velázquez et al., 2015). Young women reporting strong migration intentions may be aware of their own discrimination and their lack of opportunities (Ryussen \& Salomone, 2018) which in turn may explain 
their higher alcohol use. This possible association merits further research as it has important programmatic and policy implications.

From an exosystemic perspective (Bronfenbrenner, 1992) we identified some risk factors for alcohol use for the overall sample. Youth (male and female) who spoke English as a second language at home had a significantly higher odds of having a drinking experience. We treat the use of English at home, as a proxy for family migration to the USA. As such, this finding is consistent with previous research in the topic, which tends to identify migration as a risk factor for alcohol and other drug use (Borges et al., 2007, 2009; Borges et al., 2012a), particularly among returnees. While self-reporting better health was associated with a significantly lower odds of having a drinking experience.

More unanticipated was the finding about household size, the more individuals in the household the higher the odds of using alcohol for the adolescents. This could be related to the high number of family members that were deported or self-deported back to Mexico (Denier \& Masferrer, 2020). The new comers such as uncles contribute to increase of the household size and may be introducing certain alcohol behaviors (Borges et al., 2011). Perhaps household size also might weakened or diffuse parental monitoring among many different adults such as uncles, aunts and grandparents. Furthermore, household size maybe be a proxy for lower SES, longer workdays for parents and other related phenomena that may be weakening parental monitoring. From an home economics perspective (Hazán, 2014), we interpret household size as a potential motivator for migration; as young people become aware of the financial needs of the larger families they might see migration as the only viable venue to help.

Developmental factors of interest such as older age - as expected-predicted higher alcohol use for both boys and girls. Gendered analysis revealed more nuanced differences. For example, being male, older, and using English as a second language at home were associated with significantly higher odds of having a drinking experience. For males, perceiving that living in the U.S. is bad was associated with a significantly higher odds of drinking alcohol. Further research is needed about the experiences of youth who returned to Mexico after living for long periods or all their lives in the U.S. English speaking at home could be a proxy for deportation or self-deportation (Caldwell, 2019). Traumatic migration experiences may be associated with some of the identified behaviors and attitudes, which merit additional research to inform policy and the design of interventions addressing those needs.

\section{Limitations}

The lack of research regarding the phenomenon makes this study important despite some limitations. A main limitation is the cross-sectional nature of the study and our inability to infer causality. Are youth who drink more likely to have intentions to migrate or vice versa? The lack of a specific measure about parental supervision and involvement in our models also limits our interpretation of some of the findings of the study. Future research will include measures that are more specific regarding parenting. The main constructs of the study were recoded to be dichotomous variables and as such, they limited the ability to capture variance. The key constructs of intentions to migrate and alcohol use in the past were measured through single items, which presents some potential limitations such as lower content validity, sensitivity (somehow addressed by the large sample size), and reliability.

The sample was limited to one state in Mexico, which limits the generalizability to areas of the country with unique contextual differences such as states in the northern and southern borders. Because Jalisco was identified as the third state with the highest substance use risk score (IRMCD) in Mexico (Rodríguez-Kuri et al., 2019), these findings may applicable to the other high substance use risks states.

\section{Implications}

This study makes an important contribution to our understanding of the etiology of migration intentions and health for adolescents living in sending migration communities. The findings confirm previous research but also contribute more nuance to the association of migration and specific behaviors such as alcohol use that affect youths' health.

The findings provide information about the lived experience of young people in historically migrant communities in Mexico. From an ecological systems perspective, this study highlights the interconnectedness of different ecological systems and their influence on the wellbeing of young people. Youth from families in communities with high rates of migration appear to have unique vulnerabilities and assets. The individual youths are part of families in flux, experience changing gender norms, live in poor communities with limited employment opportunities, and need to navigate unpredictable U.S. immigration policies.

Although the study focused on one potential youth risk behaviour-alcohol use-it documented the broader complexity of the lived experience of youth from migrant communities. Prevention and treatment interventions can benefit from these findings, for example, by tailoring services to the unique perceptions and experiences of young people and families living in high migratory communities. 
These findings can inform the contextual adaptation of existing evidence based substance abuse prevention interventions for Mexican youth. Mexico is a large country with regional differences in terms of protective and risk factors. Efficacious interventions may benefit for a second level of contextual adaptation in states with the highest rates of migration, such as Jalisco. Youth who wish to migrate, regardless of their past, present or future migration histories could benefit from culturally congruent prevention interventions.

The findings confirmed important gender differences and similarities in terms of protective and risk factors associated with intentions to migrate and alcohol use. Young women and men need support as they attempt to reconcile more traditional and contemporary expectations imposed on them by their families, communities and social media (Velleman, 2009).

This study confirms that the association between intentions to migrate and alcohol continues to be predominantly a male phenomenon but not exclusively. Future research will help us better understand the experiences of young women living in high migration communities and the ways in which they cope with the different demands and challenges they face.

These findings have important policy implications related to youth who are dreaming about migrating and to those who returned to Mexico after having a migration experience. Returned migrant youth and their local peers could benefit for policies that support them to be successful in in their education and employment experiences in their own communities. Successful young people will not think as much about migrating or being involve in risky behaviors. Such policies and related programs need resources. The Mexican and USA governments together could fund such evidencebased programs. The youth, their families, their communities and both countries could benefit from the investment.

As these findings show, young people are highly resilient, future research needs to continue to advance knowledge not only about risk factors but also about the protective factors associated with migration and good health. Future interventions will benefit from such knowledge, the assets and strengths of Mexican youth from migrant communities can be their foundation.

\section{Conclusion}

The findings of this study are confirmatory of previous research and at the same time shine new light into the changing youth immigration and health landscape. Twenty percent of the pre-adolescents and adolescents in the study expressed an interest in migrating to the U.S. The results show an association between their intentions to migrate and using alcohol in the past. Boys continue to be at higher risk than girls are, but females appear to be increasing their risk level. Mexico and the U.S. are neighbors with a long shared history and population. These findings call for more cooperation between the two countries to assure that young people can grow-up to be productive and healthy citizens in both countries.

Acknowledgement This study is part of the Family Migration Context, Aspirations and Children's Schooling (FAMELO): Mexico, Mozambique \& Nepal. Funded by the Eunice Kennedy Shriver National Institute of Child Health \& Human Development (NICHD) of the National Institutes of Health (NIH). P01HD080659 and P2CHD041025. PI: Glick. J.

\section{References}

Bach, A. J. (2020). Vulnerable youth in volatile times: Ethical concerns of doing visual work with transfronterizx youth on the US/Mexico border. Review of Education, Pedagogy, and Cultural Studies, 42(3), 198-216.

Bermúdez, J., \& Reyes, A. (2015). Inmigrantes mexicanos en Estados Unidos. Una revisión del perfil sociodemográfico de la migración reciente, 1995-2015. En: CONAPO (Ed). La situación demográfica de México, 2015.

Bertoli, S., \& Ruyssen, I. (2018). Networks and migrants' intended destination. Journal of Economic Geography, 18, 705-728.

Borges, G., Breslau, J., Orozco, R., Tancredi, D. J., Anderson, H., Aguilar-Gaxiola, S., \& Mora, M.-E.M. (2011). A cross-national study on Mexico-US migration, substance use and substance use disorders. Drug and Alcohol Dependence, 117, 16-23.

Borges, G., Cherpitel, C. J., Orozco, R., Zemore, S. E., Wallisch, L., Medina-Mora, M. E., \& Breslau, J. (2016). Substance use and cumulative exposure to American society: Findings from both sides of the US-Mexico border region. American Journal of Public Health, 106(1), 119-127.

Borges, G., Medina- Mora, M. E., Orozco, R., Fleiz, C., Cherpitel, C., \& Breslau, J. (2009). The Mexican migration to the United States and substance use in northern Mexico. Addiction, 104(4), 603-611.

Borges, G., Medina-Mora, M. E., Breslau, J., \& Aguilar-Gaxiola, S. (2007). The effect of migration to the United States on substance use disorders among returned Mexican migrants and families of migrants. American Journal of Public Health, 97(10), 1847-1851.

Borges, G., Orozco, R., Rafful, C., Miller, E., \& Breslau, J. (2012a). Suicidality, ethnicity and immigration in the USA. Psychological Medicine, 42, 1175-1184.

Borges, G., Rafful, C., Benjet, C., Tancredi, D. J., et al. (2012b). Mexican immigration to the US and alcohol and drug use opportunities: Does it make a difference in alcohol and/or drug use? Drug and Alcohol Dependence, 25(125), S4-S11.

Borges, G., Zemore, S. E., Orozco, R., Cherpitel, C. J., Martínez, P., \& Wallisch, L. (2018). Drug use on both sides of the US-Mexico border. Salud Pública de México, 60, 451-461.

Bronfenbrenner, U. (1992). Ecological systems theory. In R. Vasta (Ed.), Six theories of child development: Revised formulations and current issues. (pp. 187-249). Jessica Kingsley Publishers.

Bronfenbrenner, U. (2005). Making human beings human: Bioecological perspectives on human development. . Thousand Oaks: Sage Publications.

Buechler, S., \& Lutz-Ley, A. (2020). Livelihoods with multiple stressors: Gendered youth decision-making under global change in 
rural northwest Mexico. Environment and Planning E: Nature and Space, 3(4), 1096-1119.

Caldwell, B. C. (2019). Deported Americans: Life after deportation to Mexico. Duke University Press.

Carling, J. (2017). How does migration arise? In M. McAuliffe, \& M. Klein Solomon (Conveners) (Eds.), Ideas to inform international cooperation on safe, orderly and regular migration, IOM: Geneva Pew Research Center.

Centers for Disease Control and Prevention (CDC). (2018a). Fact sheets-Alcohol use and youth health. https://www.cdc.gov/alcoh ol/fact-sheets/alcohol-use.htm

CDC. (2018b). Fact sheets-Underage drinking. https://www.cdc.gov/ alcohol/fact-sheets/underage-drinking.htm

Chu, H., \& Thelamour, B. (2021). Introduction: Contextualizing immigration using bioecological systems theory. In H. Chu \& B. Thelamour (Eds.), Conceptual and methodological approaches to navigating immigrant ecologies. Advances in immigrant family research. Cham: Springer.

CONAPO. (2016). Datos abiertos del índice de marginación, México 1990-2015. CONAPO.

Consejo Nacional de Población (CONAPO). (2015). Anuario de migración y remesas, México 2014. CONAPO.

Creighton, M. J. (2013). The role of aspirations in domestic and international migration. The Social Science Journal, 50(1), 79-88.

Dabir, M., Daroudi, I., \& Khazri, M. D. (2013). Impact of migration in economic and social of rural environments. International Research Journal of Applied and Basic Sciences, 7(5), 288-298.

Dao, T. H., Docquier, F., Parsons, C., et al. (2018). Migration and development: Dissecting the anatomy of the mobility transition. Journal of Development Economics, 132, 88-101.

de Haas, H. (2010). The internal dynamics of migration processes: A theoretical inquiry. Journal of Ethnic and Migration Studies, $36,1587-1617$

Denier, N., \& Masferrer, C. (2020). Returning to a new Mexican labor market? Regional variation in the economic incorporation of return migrants from the U.S. to Mexico. Population Research Policy Review, 39, 617-641.

Deykin, E. Y., Levy, J. C., \& Wells, V. (1987). Adolescent depression, alcohol and drug abuse. American Journal of Public Health, 77(2), 178-182.

Durand, J., Massey, D. S., \& Zenteno, R. M. (2001). Mexican immigration to the United States: Continuities and changes. Latin American Research Review, 36(1), 107-127.

Escobar, E. R., Bustos Gamiño, M., Salazar, R. X., Soto Hernández, I., et al. (2018). National trends in alcohol consumption in Mexico: Results of the national survey on drug, alcohol and tobacco consumption 2016-2017. Salud Mental, 41(1), 7-15.

Esipova, N., Ray, J., \& Pugliese, A. (2011a). Gallup world poll: The many faces of global migration. IOM Migration Research Series. No. 43. International Organization for Migration.

Esipova, N., Ray, J., \& Srinivasan, R. (2011). The world's potential migrants-Who they are. . Gallup Inc.

Gonzalez-Barrera, A., \& Krogstad, J. M. (2018). Fact tank: What we know about illegal immigration from Mexico. http://www.pewre search.org/fact-tank/2018/12/03/what-we-know-about-illegalimmigration-from-Mexico/

Guo, S., \& Fraser, M. W. (2015). Propensity score analysis: Statistical methods and applications. (2nd ed.). Sage Publications.

Hamilton, E. (2020). Migration and mental health in Mexico: Domestic migrants, return US migrants, and non-migrants. Frontiers in Psychiatry, 10, 970.

Hazán, M. (2014). Understanding return migration to Mexico: Towards a comprehensive policy for the reintegration of returning migrants. https://escholarship.org/content/qt5nd4q6n3/ qt5nd4q6n3.pdf
Instituto Nacional de Psiquiatría Ramón de la Fuente Muñoz; Instituto de Salud Pública, Comisión Nacional Contra las Adicciones, Secretaría de Salud. (2017). Encuesta Nacional de Consumo de Drogas (ENCODAT). Alcohol y Tabaco 2016-2017: Reporte de Alcohol.

Jennissen, R. (2007). Causality chains in the international migration systems approach. Population Research and Policy Review, 26(4), 411-436.

Jensen, B., Giorguli Saucedo, S., \& Hernández Padilla, E. (2018). International migration and the academic performance of Mexican adolescents. International Migration Review, 52(2), 559-596.

Kandel, W., \& Massey, D. S. (2002). The culture of Mexican migration: A theoretical and empirical analysis. Social Forces, 80(3), 981-1004.

Khantzian, E. J. (1985). The self-medication hypothesis of addictive disorders: Focus on heroin and cocaine dependence. The American Journal of Psychiatry, 142(11), 1259-1264.

Klee, H., \& Reid, P. (1998). Drug use among the young homeless: Coping through self-medication. Health, 2(2), 115-134.

Kulis, S., Marsiglia, F. F., Ayers, S., Booth, J., \& Nuño-Gutiérrez, B. (2012). Drug resistance and substance use among male and female adolescents in alternative secondary schools in Guanajuato, Mexico. Journal of Studies on Alcohol and Drugs, 73, 111-119.

Kulis, S. S., Marsiglia, F. F., Nuño-Gutiérrez, B. L., Lozano, M. D., $\&$ Median-Mora, M. E. (2018). Traditional gender roles and substance-use behaviors, attitudes, exposure, and resistance among early adolescents in large cities of Mexico. Journal of Substance Use, 23, 471-480.

Levitt, P. (1998). Social remittances: Migration driven local-level forms of cultural diffusion. International Migration Review, 32(4), 926-948.

Levitt, P. (2001). The transnational villagers. University of California Press.

Leyva-Flores, R., Gutierrez, J. P., Infante, C., Gonzalez-Vazquez, T., \& Magaña-Valladares, L. (2018). Household wellbeing and health risks in Mexican households with and without migrants: a crosssectional analysis. Public Health Reviews, 39(1), 1-11.

Manchin, M., \& Orazbayev, S. (2018). Social networks and the intention to migrate. World Development, 109, 360-374.

Markšaityte, R. (2010). The importance of psychological and social characteristics on emigrational intentions and emigration of Lithuanians (Doctoral dissertation, Vytautas Magnus University).

Marshall, E. J. (2015). Adolescent alcohol use: Risks and consequences. Alcohol and Alcoholism, 49(2), 160-164.

Marsiglia, F. F., Ayers, S., Hoffman, S., \& Urbaeva, Z. (2012). Understanding the gender patterns of substance use initiation among adolescents living in Mexico. International Journal of Drug Policy, 23, 251-254.

Marsiglia, F. F., Kulis, S., Hoffman, S., Calderón, C., Becerra, D., \& Âlvarez, D. (2011). Migration intentions and illicit substance use among youth in central Mexico. Substance Use \& Misuse, 46, $1619-1627$.

Marsiglia, F. F., Medina-Mora, M. E., Gonzalvez, A., Alderson, G., Harthun, M., Ayers, S., Nuño Gutiérrez, B., Corona, M. D., Mendoza Melendez, M. A., \& Kulis, S. (2019). Binational cultural adaptation of the keepin' it REAL substance use prevention program for adolescents in Mexico. Prevention Science, 20, $1125-1135$.

Martinez-Donate, A. P., Verdecias, N., Zhang, X., Jesús, E., GonzalezFagoaga, E., et al. (2020). Health profile and health care access of Mexican migration flows traversing the northern border of Mexico. Medical Care, 58(5), 474-482.

Martínez-Schuldt, R. D., \& Martínez, D. E. (2020). Destination intentions of unauthorized Mexican border crossers and familial ties to us citizens. The Sociological Quarterly. https://doi.org/10.1080/ 00380253.2020.1733448. 
Masferrer, C., \& Roberts, B. R. (2012). Going back home? Changing demography and geography of Mexican return migration. Population Research and Policy Review, 31(4), 465-496.

Massey, D. S., Arango, J., Hugo, G., Kouaouci, A., Pellegrino, A., \& Taylor, J. E. (1993). Theories of international migration: A review and appraisal. Population and Development Review, 19(3), 431-466.

Massey, D. S., Arango, J., Hugo, G., Kouaouci, A., Pellegrino, A., \& Taylor, J. E. (1994). An evaluation of international migration theory: The North American case. Population and Development Review, 20(4), 699-751.

Migali, S., \& Scipioni, M. (2018). A global analysis of intentions to migrate. European Commission.

Migali, S., \& Scipioni, M. (2019). Who's about to leave? A global survey of aspirations and intentions to migrate. International Migration, 57, 181-200.

Pew Research Center. (2019a). Mexicans decline to less than half the U.S. unauthorized immigrant population for the first time. Fact Tank, June12, 2019.

Pew Research Center. (2019b). Key findings about U.S. immigrants. Fact Tank, June 17, 2019.

Rodríguez-Kuri, S. E., García-Aurrecoechea, R., Benítez-Villa, J. L., \& Fernández Cáceres, C. (2019). Diagnosis of macrosocial risks of drug use in Mexican municipalities. Salud Mental, 42, 5-12.

Rosenbaum, P. R., \& Rubin, D. B. (1985). Constructing a control group using multivariate matched sampling and regression adjustment to remove bias in observational studies. The American Statistician, 39, 33-38.

Ruyssen, I., \& Salomone, S. (2018). Female migration: A way out of discrimination? Journal of Development Economics, 130, 224-241.

Tjaden, J., Auer, D., \& Laczko, F. (2019). Linking migration intentions with flows: Evidence and potential use. International Migration, $57,36-57$
Van Dalen, H. P., \& Henkens, K. (2013). Explaining emigration intentions and behavior in the Netherlands. Population Studies, 67(2), $225-241$.

Vázquez, A. L., Domenech Rodríguez, M. M., Schwartz, S., Amador Buenabad, N. G., Bustos Gamiño, M. N., Gutierrez López, M. L., \& Villatoro Velázquez, J. A. (2019). Early adolescent substance use in a national sample of Mexican youths: Demographic characteristics that predict use of alcohol, tobacco, and other drugs. Journal of Latinx Psychology, 7(4), 273-283.

Velleman, R. (2009). Influences on how children and young people learn about and behave towards alcohol: A review of the literature for the Joseph Rowntree Foundation (Part One). . London: Joseph Rowntree Foundation.

Villatoro-Velázquez, J. A., Fregoso, D., Bustos, M., Oliva, N., Mujica, A., del Campo, R., \& Medina-Mora, M. E. (2015). Encuesta Nacional de Consumo de Drogas en Estudiantes 2014: Reporte de Alcohol. Instituto Nacional de Psiquiatría Ramón de la Fuente Muñiz, Instituto Nacional de Salud Pública, Comisión Nacional Contra las Adicciones, Secretaría de Salud. México DF, México: INPRFM ISBN, 978-607.

Wu, L. T., Schlenger, W. E., \& Galvin, D. M. (2003). The relationship between employment and substance use among students aged 12 to 17. Journal of Adolescent Health, 32(1), 5-15.

Zullig, K. J., Valois, R. F., Huebner, E. S., Oeltmann, J. E., \& Drane, J. W. (2001). Relationship between perceived life satisfaction and adolescents' substance abuse. Journal of Adolescent Health, 29, 279-288.

Publisher's Note Springer Nature remains neutral with regard to jurisdictional claims in published maps and institutional affiliations. 